\title{
Ministernotomy versus conventional sternotomy for aortic valve replacement: A systematic review and meta-analysis
}

\author{
Morgan L. Brown, MD, Stephen H. McKellar, MD, Thoralf M. Sundt, MD, and Hartzell V. Schaff, MD
}

Objective: Most aortic valve replacements are by conventional full median sternotomy. Less invasive approaches have been developed with partial upper sternotomy (ministernotomy).

\begin{abstract}
Methods: Systematic review and meta-analysis were performed with studies comparing ministernotomy and full sternotomy for aortic valve replacement.

Results: Twenty-six studies were selected, with 4586 patients with aortic valve replacement (2054 ministernotomy, 2532 full sternotomy). There was no difference in mortality (odds ratio $0.71,95 \%$ confidence interval 0.49 1.02). Ministernotomy had longer crossclamp and bypass times (weighted mean difference 7.90 minutes, $95 \%$ confidence interval 3.50-10.29 minutes, and 11.46 minutes, 95\% confidence interval 5.26-17.65 minutes, respectively). Both intensive care unit and hospital stays were shorter with ministernotomy (weighted mean difference -0.46 days, $95 \%$ confidence interval -0.72 to -0.20 days, and -0.91 days, $95 \%$ confidence interval -1.45 to -0.37 days, respectively). Ministernotomy had shorter ventilation time and less blood loss within 24 hours (weighted mean difference -2.1 hours, $95 \%$ confidence interval -2.95 to -1.30 hours, and $-79 \mathrm{~mL}, 95 \%$ confidence interval -23 to $136 \mathrm{~mL}$, respectively). Randomized studies tended to demonstrate no difference between ministernotomy and full sternotomy. Rate of conversion from partial to conventional sternotomy was $3.0 \%$ ( $95 \%$ confidence interval $1.8 \%-.4 \%$ ).
\end{abstract}

Conclusion: Ministernotomy can be performed safely for aortic valve replacement, without increased risk of death or other major complication; however, few objective advantages have been shown. Surgeons must conduct well-designed, prospective studies of relevant, consistent clinical outcomes to determine the role of ministernotomy in cardiac surgery.

Most aortic valve replacements (AVR) are generally performed through a conventional full median sternotomy. There have been many attempts, however, to make the procedure less invasive by reducing incision size and keeping a portion of the sternum intact. Techniques include partial upper and lower sternotomies, small anterolateral thoracotomies, parasternal incisions, and transverse sternotomies. The most common minimally invasive approach is a partial upper sternotomy (ministernotomy).

Through a ministernotomy approach, skin incisions are shorter, arguably improving cosmetic results. ${ }^{1,2}$ Additionally, it has been argued that despite lengthier operations with a ministernotomy approach, patients have improved outcomes, including less bleeding, reduced ventilation time, and reduced intensive care unit (ICU) and hospital

From the Division of Cardiovascular Surgery, Mayo Clinic, Rochester, Minn. Received for publication Jan 31, 2008; revisions received June 18, 2008; accepted for publication Aug 5, 2008.

Address for reprints: Hartzell V. Schaff, MD, 200 1st St SW, Rochester MN 55905 (E-mail: schaff@mayo.edu).

J Thorac Cardiovasc Surg 2009;137:670-9

$0022-5223 / \$ 36.00$

Copyright (C) 2009 by The American Association for Thoracic Surgery doi: 10.1016/j.jtcvs.2008.08.010 stays. This may be due to maintenance of the integrity of the chest wall. ${ }^{1,2}$ Our objective was to perform a systematic review and meta-analysis of studies comparing AVR through a ministernotomy and a full median sternotomy approaches.

\section{MATERIALS AND METHODS \\ Searching for Studies}

Only published articles were selected for inclusion. Medline (1950 week 2 to January 22, 2007), Embase (1988 to week 3 2007), the Cochrane Controlled Clinical Trials Register (through fourth quarter 2006), and PubMed (through January 22, 2007) databases were searched. Two themes were developed and combined with the Boolean operator " and.' 'The first term was aortic valve or aorta valve, with both exploded medical subject headings and keyword search for either term. The second term was surgical procedure, minimally invasive (MeSH term) and the keyword minimally invasive. Bibliographies were searched manually.

\section{Inclusion and Exclusion Criteria}

Both randomized trials and observational studies of patients undergoing AVR through a ministernotomy versus a full sternotomy were included. All languages were included. Studies were excluded for the following reasons: (1) More than $50 \%$ of patients underwent an incision other than a ministernotomy, such as a transverse sternotomy, thoracotomy, or minithoracotomy. (2) More than $50 \%$ of patients underwent aortic root or ascending aortic surgery. (3) There was failure to discriminate outcomes specific to aortic valves. (4) There was failure to provide comparisons between patients with full sternotomies and ministernotomies. Studies were limited to those involving human subjects. Two individuals (M.L.B. and S.H.M.) reviewed each full article for inclusion and exclusion criteria (Figure 1). A $\kappa$ of 0.93 was calculated, and disagreements were resolved by consensus. 


\section{Abbreviations and Acronyms \\ $\mathrm{AVR}=$ aortic valve replacement \\ $\mathrm{CI}=$ confidence interval \\ $\mathrm{ICU}=$ intensive care unit \\ OR = odds ratio \\ $\mathrm{WMD}=$ weighted mean difference}

\section{Quality}

All studies were assessed for quality by examining each of the following characteristics: representative nature of general population, secure ascertainment, comparability (attempts to adjust for patient characteristics), and adequate assessment of outcomes.

\section{Data Extraction}

A total of 646 abstracts were reviewed. After elimination of duplicate studies, case reports, case series, and review articles, 56 full articles were selected for complete review. A total of 30 studies were removed for the following reasons: more than $50 \%$ of patients with approaches other than an upper sternotomy (11 reports); lack of a comparative cohort (8 reports); inability to separate aortic valves from other surgery types (5 reports); unavailability of article (2 reports); multiple publications of single patient group ( 2 reports); and aortic root replacements (2 reports; Figure 1).

\section{Outcomes}

Outcomes were assessed with all studies that reported each particular outcome. The primary outcome was early mortality (within 30 days). Secondary outcomes included cardiopulmonary bypass time, crossclamp time, operative time, ventilation time, blood loss within 24 hours, ICU stay, hospital stay, pain score, cosmesis, and postoperative incidences of stroke, atrial fibrillation, mediastinitis, and sternal instability. The number of conversions from a ministernotomy to a full sternotomy was also recorded.

Ventilation time was recorded according to the authors' definitions. Volume of blood was defined as that collected in chest tubes within 24 hours or, if the duration of collection was not available, the final volume reported by the authors. ICU and hospital stays were measured from the end of surgery until ICU or hospital discharge, respectively. Atrial fibrillation and stroke were defined according to study authors' definitions. Mediastinitis and sternal instability were recorded according to author criteria both for patients who required only conservative therapy and for those who required surgical intervention.

\section{Statistical Analysis}

Continuous outcomes were analyzed as weighted mean differences (WMDs), comparative categoric outcomes were analyzed as odds ratios (ORs), and noncomparative rates were analyzed as simple proportions. Pooled effect estimates and heterogeneity between studies were analyzed by use of RevMan (v4.2; Cochrane Collaboration, Oxford, UK) or StatsDirect (StatsDirect Ltd, Altrincham, UK). The pooled proportion was calculated as the back transformation of the weighted mean of the transformed proportions with a DerSimonian-Laird random effects model. Statistical significance was ascribed to any confidence interval (CI) that excluded the possibility of no effect. All tests of statistical significance were 2 -sided. A random effects model was performed a priori for all outcomes.

Heterogeneity was explored with a priori subgroup analyses comparing randomized and observational studies. Tests of interaction were performed. When only median values were reported, they were considered

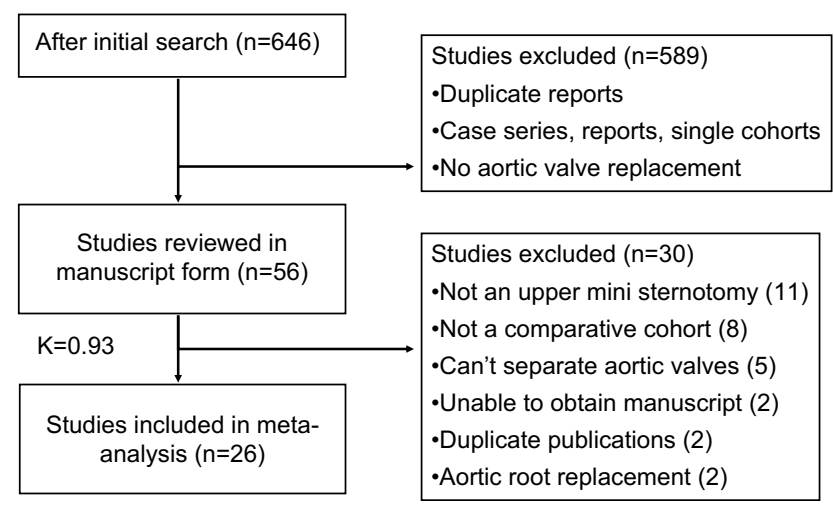

FIGURE 1. Search strategy results. In total, 28 studies were included in this review. $\kappa$, Kappa.

as the mean, and the SDs were calculated from the ranges and $P$ values reported in the article. Missing data were not imputed in this study. When there were no events in any arm of a study, a continuity correction was used.

\section{RESULTS}

A total of 26 studies were reviewed (Table 1). ${ }^{3-28}$ These studies included 2054 patients who underwent a partial upper sternotomy and 2532 patients who underwent a conventional full sternotomy. There were 4 randomized studies, ${ }^{3,6,13,21}$ although in 1 the surgeons were randomly assigned rather than the patients. ${ }^{21}$ None of these studies were blinded. The remaining 22 studies were retrospective or prospective observational trials. In only 3 observational studies was an attempt made to match patients. ${ }^{9,12,24}$ Thus in terms of quality, most studies had potential for or obvious methodologic limitations. No study reported all outcomes of interest.

\section{Early Mortality}

Twenty-four studies reported early mortality. ${ }^{3-16,18-27}$ There was no difference in early mortality between the two approaches to AVR (Figure 2). The pooled OR was 0.71 (95\% CI $0.49-1.02$ ). The 4 randomized trials had a pooled OR of 0.98 (95\% CI 0.26-3.71). Randomized and observational studies were not found to be significantly different after testing for interaction $(P=.8)$.

\section{Crossclamp, Cardiopulmonary Bypass, and Operative Times}

Both crossclamp and cardiopulmonary bypass times were slightly longer in the ministernotomy group (Figures 3 and 4). Cardiopulmonary bypass times had a pooled WMD of 11.46 minutes (95\% CI 5.26-17.65 minutes), and crossclamp times had a WMD of 7.90 minutes $(95 \%$ CI 3.50 12.29 minutes). There were no differences on subgroup analyses $(P=.3$ for both). Operative time was also significantly different between the two surgical approaches (WMD 15.58 minutes, $95 \%$ CI 2.70-28.46 minutes; Figure E1). No 
TABLE 1. List of studies included in this review and meta-analysis

\begin{tabular}{|c|c|c|c|c|c|c|c|c|c|c|c|c|}
\hline \multirow[b]{2}{*}{ Reference } & \multirow[b]{2}{*}{$\begin{array}{c}\text { Study } \\
\text { type }\end{array}$} & \multicolumn{3}{|c|}{ Sternotomy } & \multicolumn{2}{|c|}{ Age (y) } & \multicolumn{2}{|c|}{ Sex $(\%$ male $)$} & \multicolumn{2}{|c|}{ Ejection fraction $(\%)$} & \multirow[b]{2}{*}{ Reop } & \multirow[b]{2}{*}{ CP } \\
\hline & & $\begin{array}{l}\text { Mini } \\
\text { (No.) }\end{array}$ & $\begin{array}{l}\text { Full } \\
\text { (No.) }\end{array}$ & Type & Mini & Full & Mini & Full & Mini & Full & & \\
\hline Aris, ${ }^{3} 1999$ & $\mathrm{R}$ & 20 & 20 & Reverse $\mathrm{L}$ or $\mathrm{C}$ & $66.5 \pm 10$ & $62.2 \pm 12$ & NA & NA & $62.3 \pm 11$ & $64.9 \pm 13$ & 0 & 0 \\
\hline Bonacchi, ${ }^{5} 2002$ & $\mathrm{R}$ & 40 & 40 & Reverse $\mathrm{L}$ or $\mathrm{C}$ & $62.6 \pm 9.5$ & $64 \pm 12.4$ & NA & NA & $62.6 \pm 9.5$ & $64 \pm 12.4$ & 0 & 0 \\
\hline Dogan, ${ }^{13} 2003$ & $\mathrm{R}$ & 20 & 20 & Reverse L & $65.7 \pm 1.9$ & $64.3 \pm 2.9$ & 22.5 & 27.5 & $64 \pm 3$ & $65 \pm 2$ & NA & NA \\
\hline Mächler, ${ }^{21} 1999$ & RS & 60 & 60 & L-shaped & $65 \pm 11.7^{*}$ & $65 \pm 12.5^{*}$ & 58.3 & 60 & $67 \pm 15.3^{*}$ & $63 \pm 14.8^{*}$ & 0 & 0 \\
\hline Bakir, ${ }^{4} 2006$ & $\mathrm{O}$ & 232 & 274 & J-shaped & $68.7 \pm 9.2$ & $71 \pm 10.7$ & 51.7 & 56.2 & NA & NA & 0 & 0 \\
\hline Byrne, ${ }^{6} 1999$ & $\mathrm{O}$ & 20 & 19 & Upper & $67 \pm 16$ & $65 \pm 14$ & 0 & 42.1 & $48 \pm 15$ & $54 \pm 14$ & $20,19 \dagger$ & $3,7 \dagger$ \\
\hline Candaele, $^{7} 2003$ & $\mathrm{O}$ & 15 & 16 & Upper & $70 \pm 2.8^{*}$ & $64 \pm 4.6^{*}$ & 66.7 & 56.3 & NA & NA & NA & NA \\
\hline Chang, ${ }^{8} 1999$ & $\mathrm{O}$ & 18 & 16 & I-shaped & $55.1 \pm 12.2^{*}$ & $56.2 \pm 10.7^{*}$ & 61.1 & 68.8 & $50 \pm 9$ & $52 \pm 8$ & 0 & 0 \\
\hline Christiansen, ${ }^{9} 1999$ & $\mathrm{O}$ & 25 & 25 & J-shaped & $64.6 \pm 11.2^{*}$ & $66.5 \pm 9.7^{*}$ & 52 & 52 & $56.3 \pm 8.93^{*}$ & $56.7 \pm 10.46^{*}$ & 0 & 0 \\
\hline Corbi, ${ }^{10} 2003$ & $\mathrm{O}$ & 30 & 70 & V-shaped & $64.2 \pm 14.1^{*}$ & $70.96 \pm 9.8^{*}$ & 66.7 & 62.9 & $55 \pm 7.18 \dagger$ & $65.36 \pm 65.1^{*}$ & 0 & 0 \\
\hline De Smet, ${ }^{11} 2004$ & $\mathrm{O}$ & 100 & 91 & J-shaped & $69.7 \pm 12.2$ & $68.3 \pm 8.9$ & 48 & 58.2 & NA & NA & NA & 0 \\
\hline Detter, ${ }^{12} 2002$ & $\mathrm{O}$ & 70 & 70 & L-shaped & $64.3 \pm 1.3$ & $64.3 \pm 1.3$ & 57.1 & 57.1 & $56.4 \pm 11.3$ & $61.8 \pm 9.8$ & 0 & 0 \\
\hline Doll, ${ }^{14} 2002$ & $\mathrm{O}$ & 176 & 258 & $\mathrm{~J}$ or RT & $59 \pm 14$ & $64 \pm 15$ & 61.4 & 62 & $58 \pm 18$ & $55 \pm 20$ & 0 & $10,12 \dagger$ \\
\hline Ehrlich, ${ }^{15} 2000$ & $\mathrm{O}$ & 6 & 21 & J-shaped & $49.2 \pm 17.9$ & $69.1 \pm 7.3$ & 100 & 47.6 & NA & NA & 0 & 0 \\
\hline Farhat, ${ }^{16} 2003$ & $\mathrm{O}$ & 50 & 50 & RT & $63 \pm 14$ & $67 \pm 12$ & 60 & 68 & $58 \pm 12$ & $57 \pm 12$ & 0 & 0 \\
\hline Imazeki, ${ }^{17} 2006$ & $\mathrm{O}$ & 52 & 8 & Upper & $59.3 \pm 12.9$ & $59.7 \pm 6.2$ & NA & NA & NA & NA & NA & NA \\
\hline Lee, ${ }^{18} 2002$ & $\mathrm{O}$ & 46 & 40 & RT & $50.1 \pm 13.9$ & $48.9 \pm 15.1$ & 67.4 & 65 & $56 \pm 15$ & $56 \pm 12$ & 0 & $31,3 \dagger$ \\
\hline Leshnower, ${ }^{19} 2005$ & $\mathrm{O}$ & 22 & 36 & RT (port access) & $69 \pm 10$ & $69 \pm 14$ & 72.7 & 52.8 & NA & NA & 0 & 0 \\
\hline Liu, ${ }^{20} 1999$ & $\mathrm{O}$ & 86 & 78 & Upper & $67 \pm 13.0^{*}$ & $67 \pm 11.7^{*}$ & 52.3 & 48.7 & NA & NA & NA & 0 \\
\hline Masiello, ${ }^{22} 2002$ & $\mathrm{O}$ & 100 & 100 & Upper & $62 \pm 12$ & $63 \pm 8$ & 58 & 56 & NA & NA & NA & 0 \\
\hline Mihaljevic, ${ }^{23} 2004$ & $\mathrm{O}$ & 526 & 516 & Upper or PS & $65 \pm 17.9^{*}$ & $66 \pm 19.1^{*}$ & 60.2 & 57.9 & $52 \pm 17.86^{*}$ & $55 \pm 19.13^{*}$ & $12,22 \dagger$ & NA \\
\hline Stamou, ${ }^{24} 2003$ & $\mathrm{O}$ & 56 & 455 & $\mathrm{~L}$ or RT & $59 \pm 5.9^{*}$ & $68 \pm 5.6 \mathrm{v}$ & 73.2 & 55.2 & NA & NA & 0 & 0 \\
\hline Suenaga, ${ }^{25} 2004$ & $\mathrm{O}$ & 24 & 18 & Upper & $65.3 \pm 11.5$ & $68.3 \pm 7.1$ & 75 & 66.7 & $63 \pm 4.1$ & $57 \pm 13$ & NA & NA \\
\hline Szwerc, ${ }^{26} 1999$ & $\mathrm{O}$ & 50 & 50 & J-shaped & $60 \pm 2$ & $63 \pm 2$ & 62 & 68 & $52.3 \pm 2.2$ & $53.7 \pm 1.9$ & NA & 0 \\
\hline Vanoverbeke, ${ }^{27} 2004$ & $\mathrm{O}$ & 174 & 97 & Upper & $62.5 \pm 11.9$ & $63 \pm 15.2$ & NA & NA & NA & NA & 0 & 0 \\
\hline Walther, ${ }^{28} 1999$ & $\mathrm{O}$ & 36 & 84 & Upper & NA & NA & NA & NA & NA & NA & NA & NA \\
\hline Total & & 2054 & 2532 & & & & & & & & & \\
\hline
\end{tabular}

All values expressed as mean \pm SD except as noted. Randomized studies are listed first. Mini, Ministernotomy; Full, full sternotomy; Reop, reoperation; $C P$, concomitant procedure(s); $R$, randomized; $N A$, not available; $R S$, randomized assignment of surgeons; $O$, observational; $P S$, parasternal; $R T$, reverse $\mathrm{T}$ shape. *Values calculated from median values and ranges. $†$ Number in ministernotomy group, number in full sternotomy group.

difference was found in the subgroup analysis between randomized and observational studies.

\section{Ventilation time}

There were 17 studies that reported ventilation times. ${ }^{3-5}$, 8-10,12-16,18,20-22,24-25 The pooled WMD was -2.13 hours (95\% CI-2.95 to -1.30 hours), indicating somewhat shorter ventilation times in the ministernotomy group (Figure 5). Randomized studies had a pooled WMD of -0.96 (95\% CI -1.93 to 0.01 minutes), and observational studies had a pooled WMD of -2.71 minutes $(95 \% \mathrm{CI}-3.80$ to -1.62$)$. A test for interaction of ventilation time in randomized and nonrandomized subgroups demonstrated a $P$ value of .02 .

\section{ICU and Hospital Stays}

Eighteen studies reported ICU stay, ${ }^{3-5,7-16,19,22,24,25,28}$ and 21 reported hospital stay. ${ }^{3-8,11-17,19,20,22-25,27,28}$ ICU stay was slightly shorter in the partial upper sternotomy group, with a WMD of -0.46 days $(95 \%$ CI -0.72 to -0.20 days; Figure E2), and there was no difference in subgroup analysis $(P>.99)$. In addition, hospital stay was shorter in the ministernotomy group in the overall pooled WMD $(-0.91$ days, $95 \%$ CI -1.45 to -0.37 days; Figure E3). When only randomized studies $(n=3)$ were included, however, there was no significant difference between the ministernotomy and full sternotomy groups $(-0.24$ days, $95 \% \mathrm{CI}-0.87$ to 0.39$)$.

\section{Blood Loss After Operation}

There was somewhat more postoperative bleeding in the conventional full sternotomy group than in the partial sternotomy group, as reported in 17 studies. ${ }^{3-6,9-11,13-16,18 \text {, }}$ 20-22,25,26 The WMD was $-79.37 \mathrm{~mL}(95 \% \mathrm{CI}-135.78$ to -22.96) in favor of the partial upper sternotomy group (Figure 6). Subgroup analysis showed no difference between randomized and observational studies $(P=.5)$.

\section{Atrial Fibrillation, Stroke, and Sternal Complications}

Thirteen studies reported incidences of postoperative atrial fibrillation, $3,6,9,11,14,16,17,21,22,24,26,2715$ reported on stroke, $^{4,8-11,13,14,16,19,21-23,25-27}$ and 20 reported on sternal complications, including infection and dehiscence. ${ }^{3-6,}$ $8-14,16,18,19,21,22,23,25-27$ The OR for postoperative atrial fibrillation was 0.87 (95\% CI 0.64-1.20; Figure E4), showing no difference between surgical approaches. Subgroups did not demonstrate any significant differences on tests of interaction 


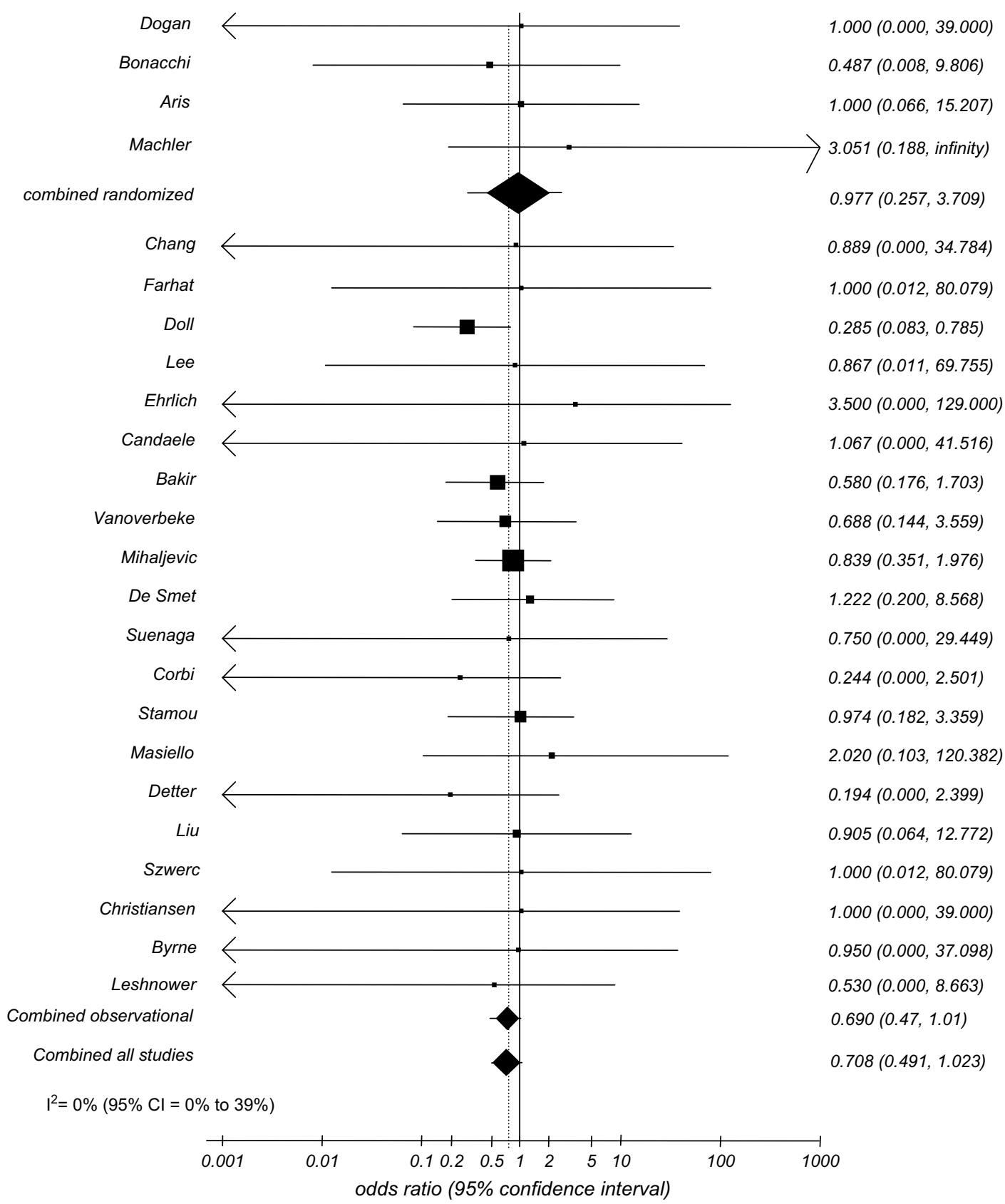

FIGURE 2. Mortality 30 days after operation. This figure demonstrates pooled estimates for 30 -day mortality. Estimates less than 1 indicate lower estimated early mortality with ministernotomy approach. This is divided into randomized and observational studies. $C I$, Confidence interval.

$(P=.8)$. There were also no difference in postoperative stroke (OR 0.91, 95\% CI 0.60-1.39) and sternal complications (OR 0.86, 95\% CI 0.49-1.49; Figures E5 and 7).

\section{Pain Scores}

Only 7 studies reported pain scores early after surgery. ${ }^{3,5,7,8,13,18,28}$ The pooled WMD was -1.67 (95\% CI -3.01 to -0.33$)$, indicating less pain with the ministernotomy approach (Figure 8). There was no differences between randomized and nonrandomized studies $(P=.1)$.

\section{Cosmesis}

Cosmesis was only quantitatively reported in 4 studies. ${ }^{3,8,12,18}$ It was not possible to pool results of cosmesis because of variation of scales including "horrible to wonderful, , ' “'all patients were satisfied,", " "very unsatisfied to very satisfied,", 12 and a visual scale. ${ }^{18}$

\section{Rate of Conversion}

The rate of conversion from partial sternotomy to conventional sternotomy was 3.0\% (95\% CI 1.8\%-4.0\%; Figure 9). 


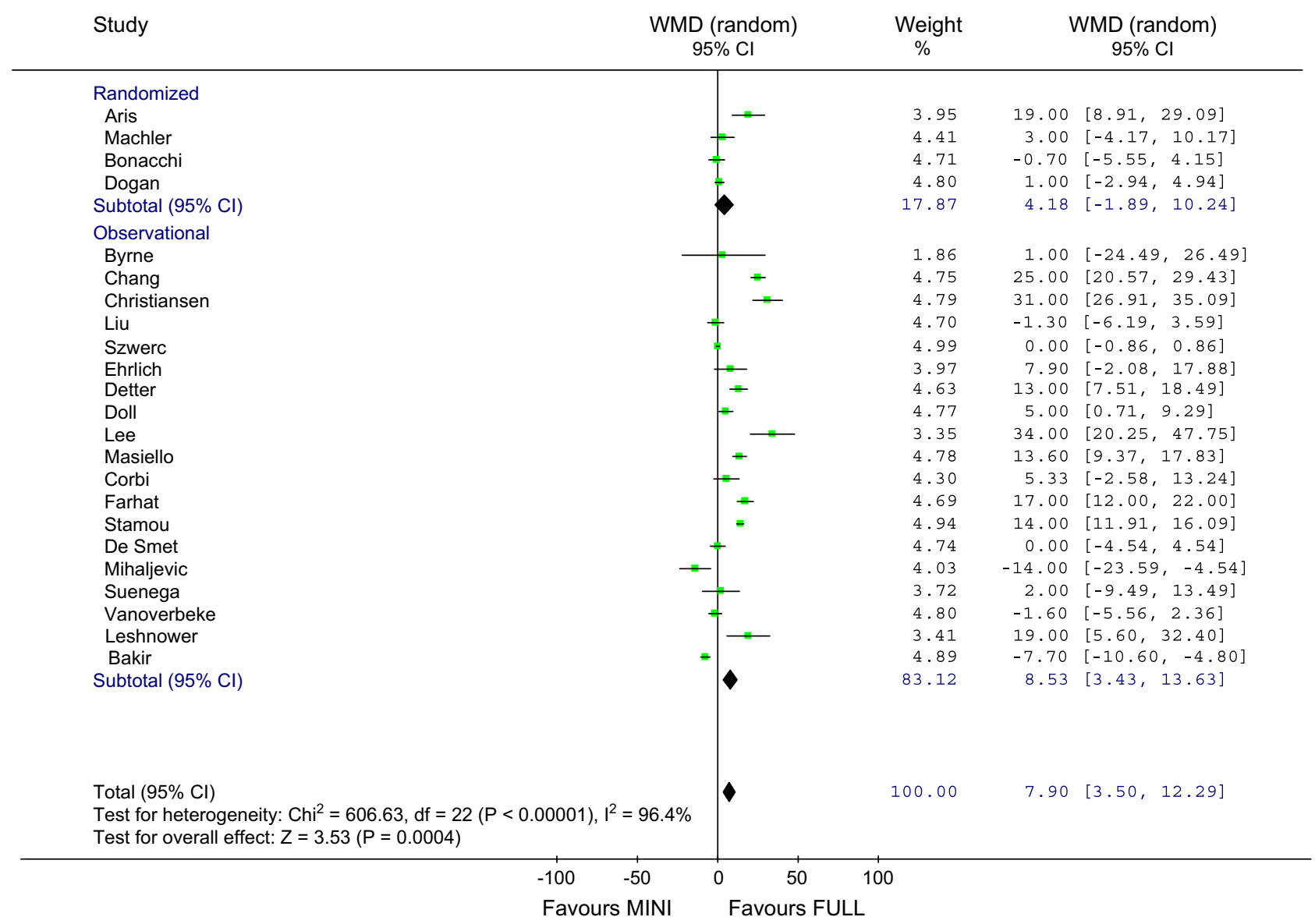

FIGURE 3. Crossclamp time (in minutes). This figure demonstrates pooled estimates for crossclamp time. Estimates greater than 1 indicate shorter crossclamp time with full sternotomy approach $(F U L L)$. This is divided into randomized and observational studies. WMD, weighted mean difference; $C I$, confidence interval; $d f$, degrees of freedom; MINI, ministernotomy.

Only 17 studies reported incidences of conversions, and most did not discuss the results of these converted operations.

\section{DISCUSSION}

This meta-analysis combined 2054 patients who underwent AVR through a partial upper sternotomy compared with 2532 patients with a full sternotomy. The results of this meta-analysis must be interpreted with some caution, however, because of significant concerns regarding the quality of most of the studies reviewed. There were only 4 randomized studies, and none were blinded. ${ }^{3,5,13,21}$ Further, many of the retrospective studies used historical controls or did not attempt to adjust for intrinsic differences related to selection bias by the operating surgeon. This demonstrates the need for surgeons to improve study quality so that accurate and precise outcomes for these and other important clinical questions can be determined. The limitations of the original studies resulted in a large amount of heterogeneity, reducing the usefulness of the pooled estimates.

This meta-analysis demonstrated no difference in early mortality between these two surgical approaches. This shows that AVR can be performed safely through a minis- ternotomy at experienced centers. Of note, there are many alternative approaches to AVR, including lower partial hemisternotomy, transverse parasternal incision, and parasternal incision. Many of these have gone out of favor, ${ }^{1,23,29}$ and this review did not examine any of these techniques.

Crossclamp and cardiopulmonary bypass times were longer in the ministernotomy group, although the differences are likely not clinically important (7.9 and 11.5 minutes). Ventilation times were shorter in the less-invasive procedures (difference of 2.1 hours). When considering only randomized studies, however, there was little difference in the duration of ventilation (WMD -0.96 hours, $95 \%$ CI -1.93 to 0.01 hours). Importantly, studies were not blinded, and little mention was made of extubation protocols, potentially confounding this finding. ICU stay was shorter in the ministernotomy group (by 11 hours), and hospital stay was also shorter in the minimally invasive group (by 1 day). This may also be related to differences in patients or bias of the treating physician, as the advantage of the ministernotomy approach diminished when looking only at the randomized studies.

There was a reduced volume of chest tube output within 24 hours in the ministernotomy group, but we were unable 


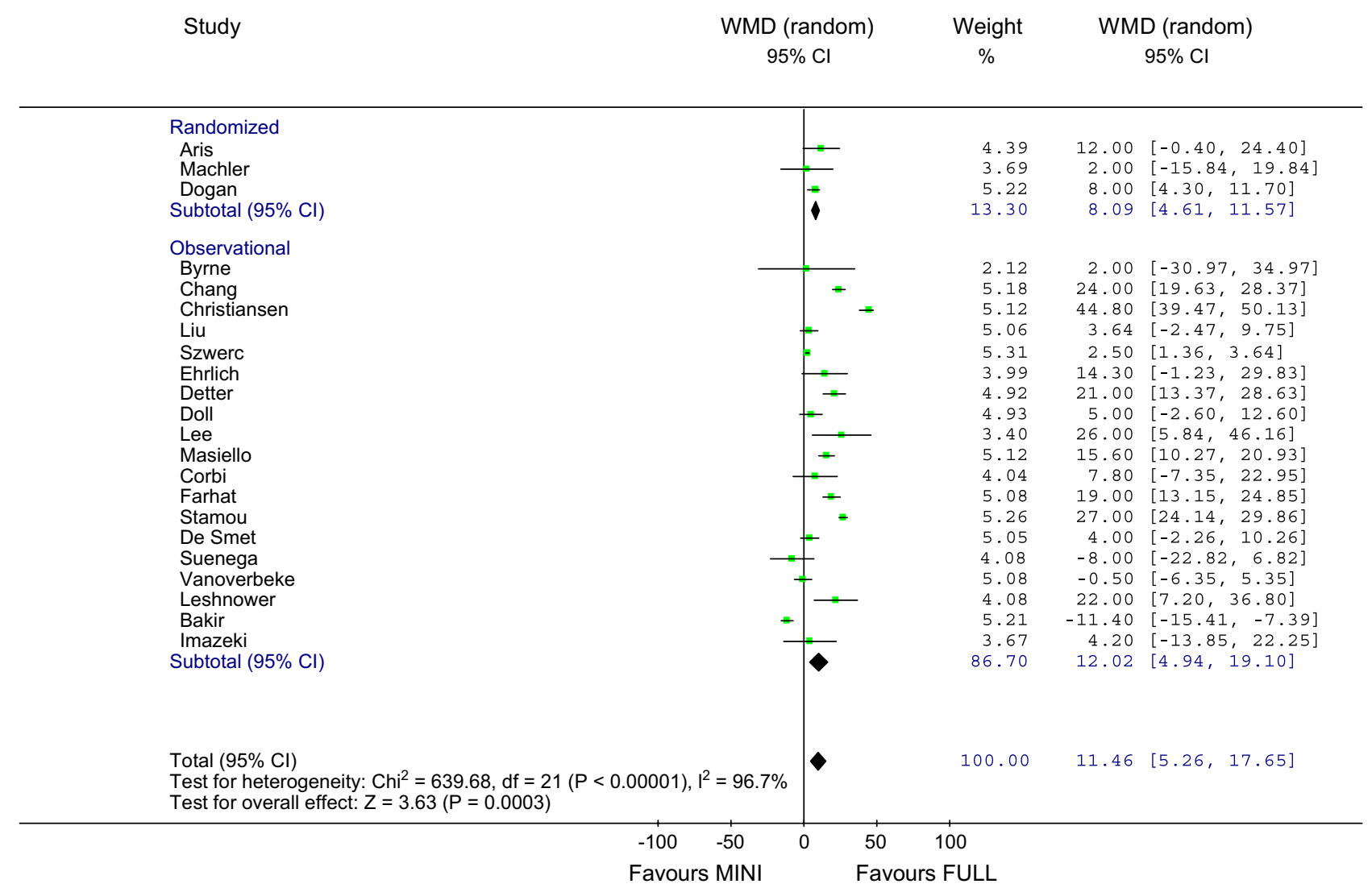

FIGURE 4. Cardiopulmonary bypass time (in minutes). This figure demonstrates pooled estimates for cardiopulmonary bypass time. Estimates greater than 1 indicate shorter bypass time with full sternotomy approach $(F U L L)$. This is divided into randomized and observational studies. WMD, weighted mean difference; $C I$, confidence interval; $d f$, degrees of freedom; MINI, ministernotomy.

to determine for most studies the more clinically important rate of blood transfusion. Decreased blood loss may be related to a decrease in surgical trauma. It is important to note that blood loss through the chest tube is not the best clinical end point, however, because the fluid collected in chest tubes may be a combination of blood and other fluids and may not be consistently measured. A more clinically useful end point would be the rate of blood transfusion according structured protocols such as those proposed in the recent clinical guidelines from the Society of Thoracic Surgeons and The Society of Cardiovascular Anesthesiologists. ${ }^{30}$ Although several studies did report blood transfusion, varying reports of timing and volume made it difficult to combine these data into a useful end point.

Studies have shown that patients have lower amounts of pain after a ministernotomy. ${ }^{5,7,8,18}$ This may be due to the lesser stretching of the sternum required in a partial sternotomy, ${ }^{1}$ which was not standardized in most of these studies. In addition, the presence or absence of sternal fractures may play an important role in early postoperative pain levels. ${ }^{1}$ Of note, few studies reported on pain $(n=7)$, the pain scoring systems varied, and the pain management strategy was not standardized in most studies. This meta-analysis found a small difference in pain scores (a 1.7 lower score on a $0-10$ scale for the ministernotomy group) after AVR. It is unclear whether such a small difference in pain scores is clinically important, and the exact cause of this difference in pain is also uncertain. With both full sternotomy and ministernotomy approaches, the sternum should always be gradually spread open the least amount to allow good visualization and avoid unnecessary bony fractures.

Some may prefer to rely on results obtained from the randomized studies. There were 4 randomized trials, ${ }^{3,5,13,21}$ which among them randomly assigned only 280 patients. These studies were published between 1999 and 2003 and were of varying quality. There were no efforts to blind surgeons in any study, and many of the end points were not standardized. Nevertheless, in these randomized studies, there was no difference between the ministernotomy and full sternotomy approaches in early mortality, crossclamp time, ventilation time, ICU stay, hospital stay, chest tube drainage within 24 hours, incidence of atrial fibrillation, postoperative pain, and incidence of sternal complications, including infection and dehiscence. Longer operative time (WMD 16 minutes) and longer cardiopulmonary bypass time (WMD 8 minutes) were found in the ministernotomy 


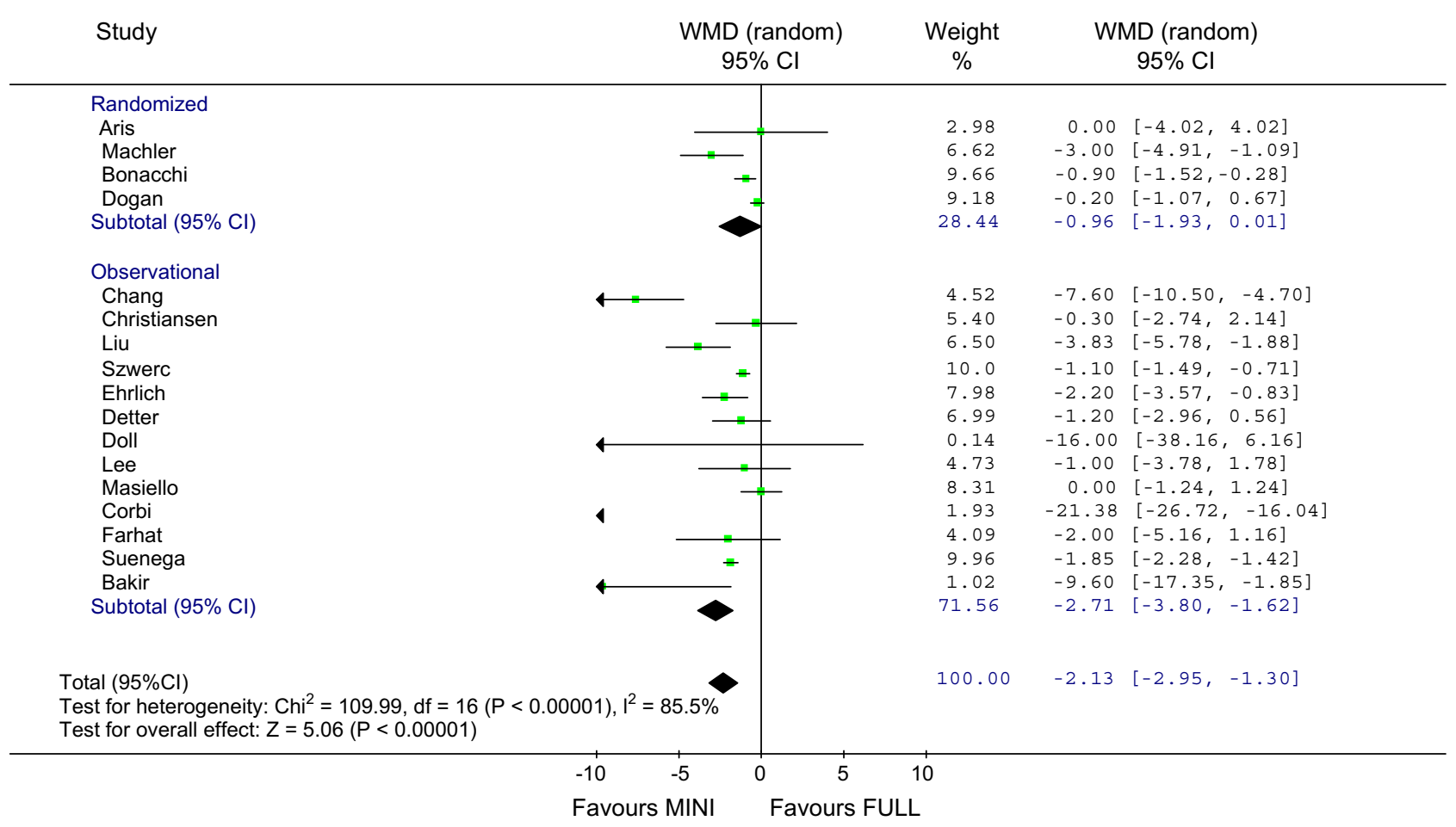

FIGURE 5. Time to extubation (in hours). This figure demonstrates pooled estimates for time to extubation. Estimates less than 1 indicate decreased time to extubation with ministernotomy approach $(M I N I)$. This is divided into randomized and observational studies. WMD, weighted mean difference; $C I$, confidence interval; $d f$, degrees of freedom; FULL, full sternotomy.

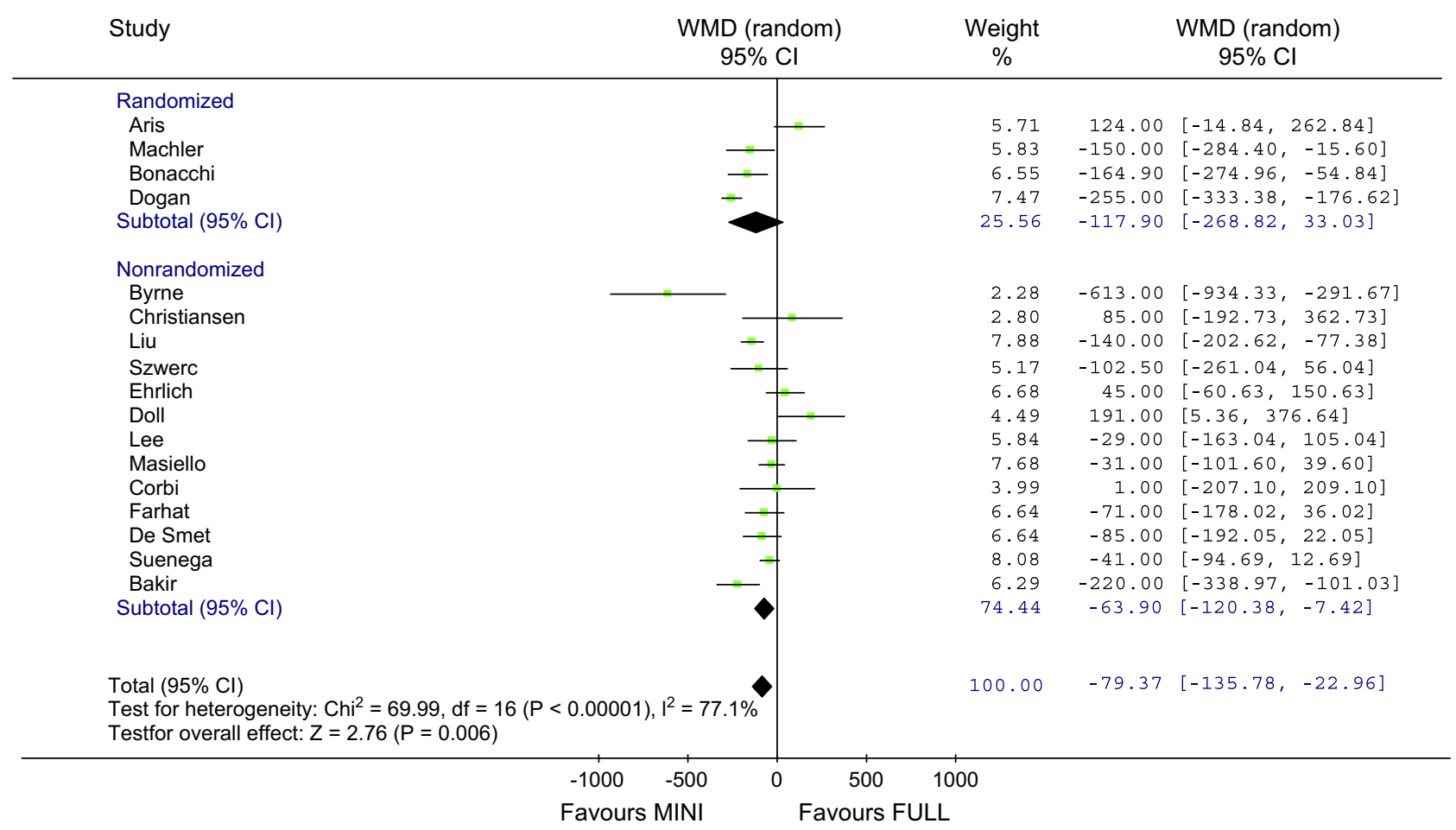

FIGURE 6. Blood loss after operation (in milliliters per 24 hours). This figure demonstrates pooled estimates for blood loss after operation. Estimates less than 1 indicate lower volume of blood loss with ministernotomy $(M I N I)$ approach. This is divided into randomized and observational studies. WMD, Weighted mean difference; $C I$, confidence interval; $d f$, degrees of freedom; FULL, full sternotomy. 


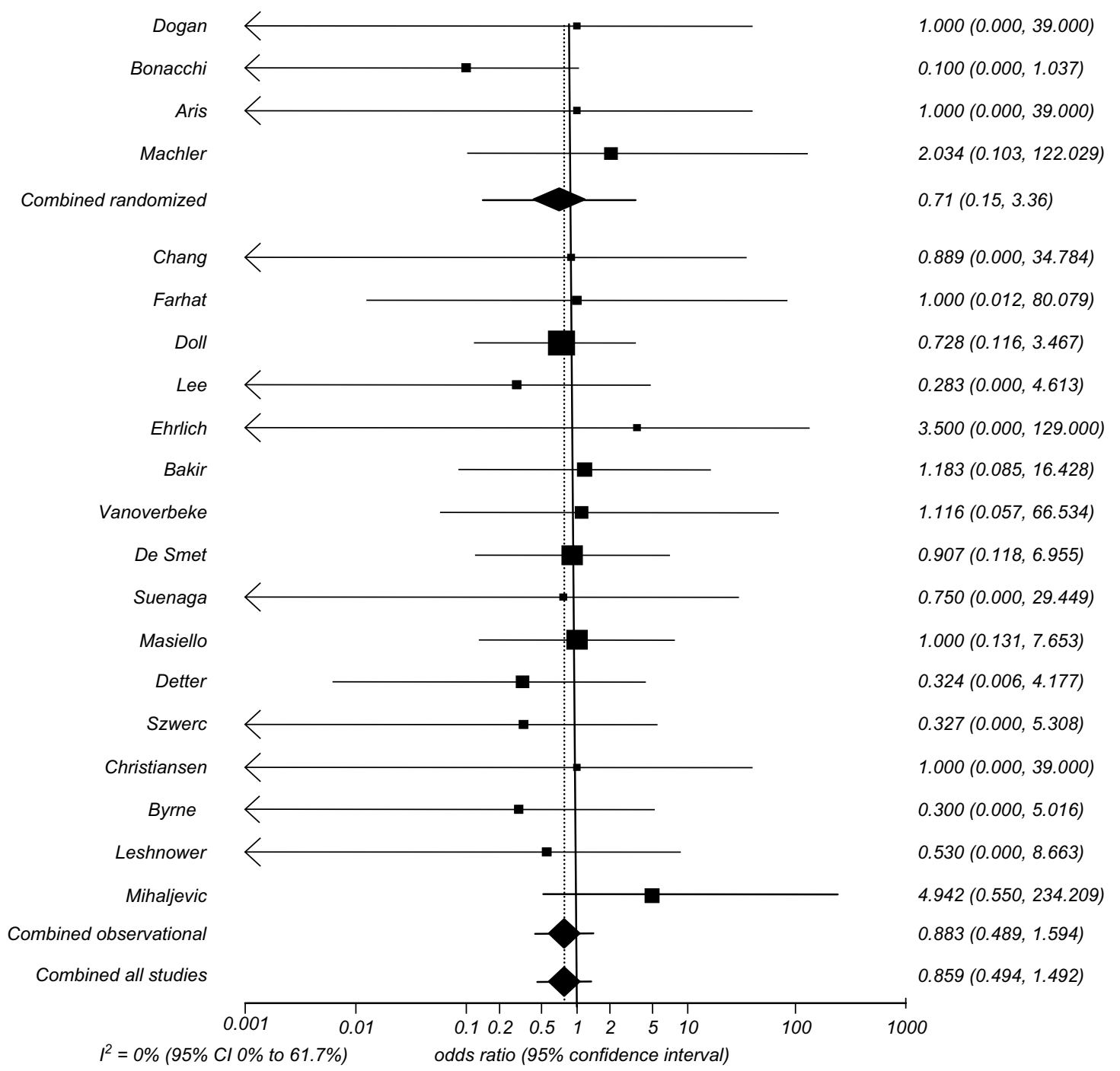

FIGURE 7. Sternal complications. This figure demonstrates pooled estimates for sternal complications, including infection and instability. Estimates less than 1 indicate lower sternal complications with ministernotomy approach. This is divided into randomized and observational studies. $C I$, Confidence interval.

group, but these differences are likely not clinically significant. Overall, the randomized studies did not demonstrate any significant difference (advantage or risk) of a ministernotomy approach to an AVR.

The shorter skin incision of minithoracotomy may intuitively appear more cosmetic, but a shorter incision is also possible with a conventional full sternotomy. ${ }^{31}$ In the study by Ehrlich and colleagues, ${ }^{15}$ after explanation of the pros and cons of ministernotomy versus full sternotomy for AVR, $78 \%$ of patients chose the full sternotomy approach, because most patients were concerned that the operating surgeon have excellent exposure during the case. Those who chose the ministernotomy approach were younger and were more concerned about the cosmetic result.

There were low rates of sternal complications for both techniques, and the conversion rate from ministernotomy to full sternotomy was $3.0 \%$. In a study from Boston, ${ }^{32} 45$ patients
$(2.6 \%)$ undergoing an upper hemisternotomy required conversion to a complete sternotomy because of bleeding, ventricular dysfunction, ventricular arrhythmia, poor exposure, or other reasons. ${ }^{32}$ Eight of these patients $(33.3 \%)$ ) died perioperatively. Thus, although conversion rates remain low, the necessity of conversion may be associated with extremely high mortality.

\section{Limitations}

This meta-analysis has several limitations. Most of these studies were observational, and many did not attempt to adjust for patient risk profiles. There was also no attempt to blind investigators in any study. We elected to report the pooled results, but the large amount of heterogeneity present does limit the usefulness of these estimates.

Studies did not always report similar outcomes, because there are no established criteria for assessing clinical utility of less-invasive cardiac surgical procedures. Such important 


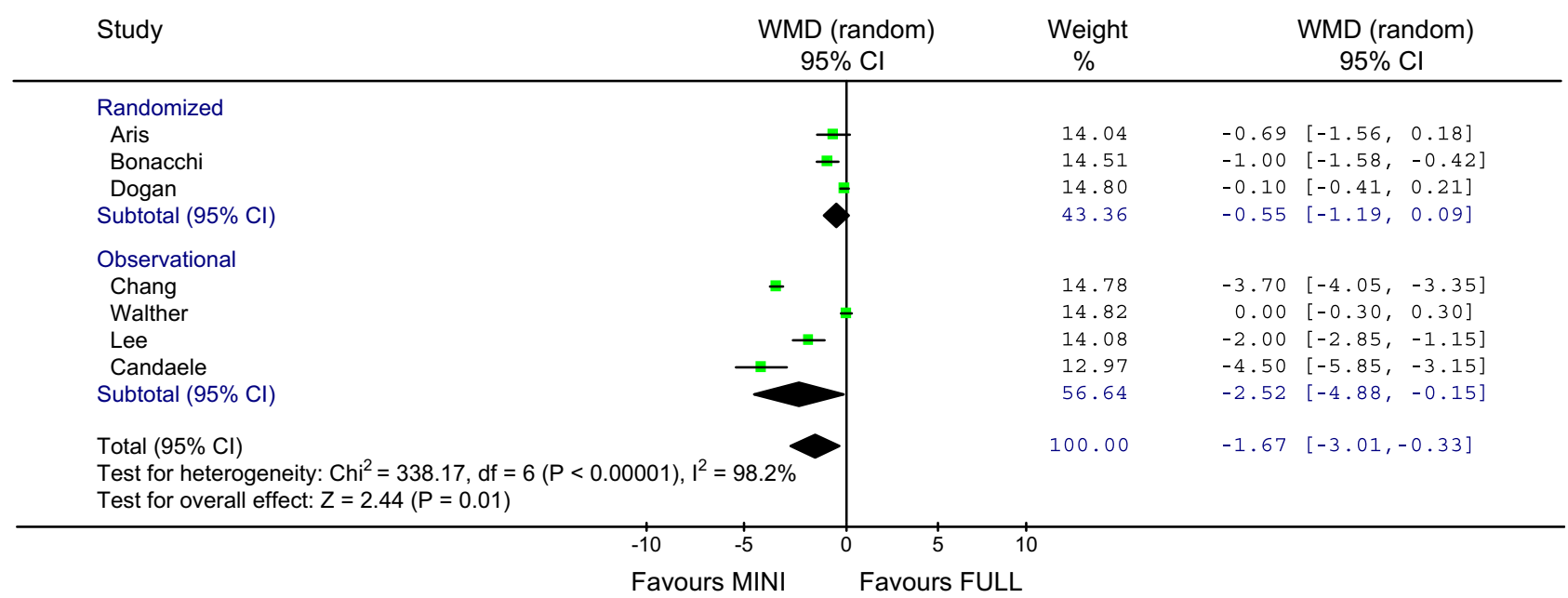

FIGURE 8. Pain scores. This figure demonstrates pooled estimates for postoperative pain scores. Estimates less than 1 indicate less pain with ministernotomy (MINI) approach. This is divided into randomized and observational studies. WMD, Weighted mean difference; $C I$, confidence interval; $d f$, degrees of freedom; FULL, full sternotomy.

measures such as quality of life and return to work were only reported in a handful of studies. These measures were reported in single-series studies, but inadequate comparisons were available. ${ }^{2,32}$ There was also limited information about long-term results, including perivalvular leaks, of the ministernotomy approach to AVR.

The impact of a learning curve is a well-documented phenomenon when new complex procedures are introduced,

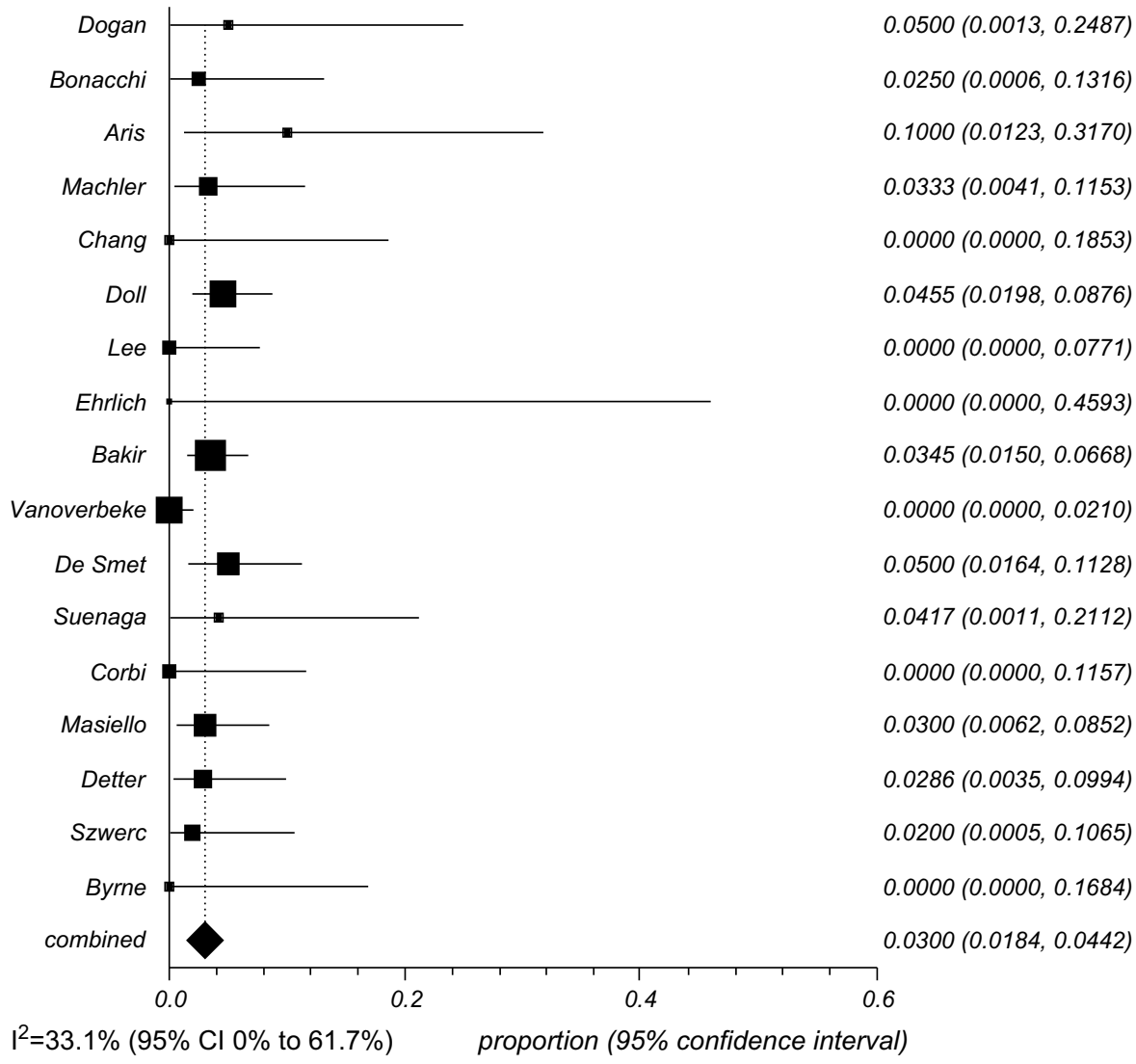

FIGURE 9. Rate of conversion. This figure demonstrates the estimated rate of conversion from a ministernotomy to full sternotomy approach. $C I$, Confidence interval. 
including minimally invasive mitral valve surgery. ${ }^{33,34} \mathrm{Be}$ cause of the nature of this review, we were unable to assess it's the impact of a learning curve on this particular procedure. In addition, we were unable to determine how many procedures each surgeon performed in a given study, or how many procedures had been performed before the study. As a consequence, we can not verify whether these surgeons were novices or experts with either the full sternotomy or ministernotomy approach.

\section{CONCLUSIONS}

This systematic review and meta-analysis showed that a less-invasive partial upper sternotomy can be performed safely, without any increase in risk of death or other major complications. There were no convincing advantages, however, of a partial upper sternotomy relative to a conventional median sternotomy for AVR. Pooled estimates demonstrated small, statistically significant differences for ventilation time, ICU stay, and hospital stay for the ministernotomy group. When only randomized studies were pooled, however, much of the advantage of the ministernotomy approach diminished. There may be less bleeding and postoperative pain with the ministernotomy approach, but this outcome needs further definition. Surgeons must conduct properly designed, prospective studies in which relevant and consistent clinical outcomes are studied.

\section{References}

1. Walther T, Falk V, Mohr FW. Minimally invasive surgery for valve disease. Curr Probl Cardiol. 2006;31:399-437.

2. Cohn LH, Adams DH, Couper GS, Bichell DP, Rosborough DM, Sears SP, et al. Minimally invasive cardiac valve surgery improves patient satisfaction while reducing costs of cardiac valve replacement and repair. Ann Surg. 1997;226: 421-8.

3. Aris A, Camara ML, Montiel J, Delgado LJ, Galan J, Litvan H. Ministernotomy versus median sternotomy for aortic valve replacement: a prospective, randomized study. Ann Thorac Surg. 999;67:1583-7.

4. Bakir I, Casselman FP, Wellens F, Jeanmart H, De Geest R, Degrieck I, et al. Minimally invasive versus standard approach aortic valve replacement: a study in 506 patients. Ann Thorac Surg. 2006;81:1599-604.

5. Bonacchi M, Prifti E, Giunti G, Frati G, Sani G. Does ministernotomy improve postoperative outcome in aortic valve operation? A prospective randomized study. Ann Thorac Surg. 2002;73:460-5.

6. Byrne JG, Aranki SF, Couper GS, Adams DH, Allred EN, Cohn LH. Reoperative aortic valve replacement: partial upper hemisternotomy versus conventional full sternotomy. J Thorac Cardiovasc Surg. 1999;118:991-7.

7. Candaele S, Herijgers P, Demeyere R, Flameng W, Evers G. Chest pain after partial upper versus complete sternotomy for aortic valve surgery. Acta Cardiol. 2003;58:17-21.

8. Chang YS, Lin PJ, Chang CH, Chu JJ, Tan PP. "I' ministernotomy for aortic valve replacement. Ann Thorac Surg. 1999;68:40-5.

9. Christiansen S, Stypmann J, Tjan TD, Wichter T, Van Aken H, Scheld HH, et al. Minimally-invasive versus conventional aortic valve replacement-perioperative course and mid-term results. Eur J Cardiothorac Surg. 1999;16:647-52.

10. Corbi P, Rahmati M, Donal E, Lanquetot H, Jayle C, Menu P, et al. Prospective comparison of minimally invasive and standard techniques for aortic valve replacement: initial experience in the first hundred patients. J Card Surg. 2003; 18:133-9.
11. De Smet JM, Rondelet B, Jansens JL, Antoine M, De Canniere D, Le Clerc JL. Assessment based on EuroSCORE of ministernotomy for aortic valve replacement. Asian Cardiovasc Thorac Ann. 2004;12:53-7.

12. Detter C, Deuse T, Boehm DH, Reichenspurner H, Reichart B. Midterm results and quality of life after minimally invasive vs. conventional aortic valve replacement. Thorac Cardiovasc Surg. 2002;50:337-41.

13. Dogan S, Dzemali O, Wimmer-Greinecker G, Derra P, Doss M, Khan MF, et al. Minimally invasive versus conventional aortic valve replacement: a prospective randomized trial. J Heart Valve Dis. 2003;12:76-80.

14. Doll N, Borger MA, Hain J, Bucerius J, Walther T, Gummert JF, et al. Minimal access aortic valve replacement: effects on morbidity and resource utilization. Ann Thorac Surg. 2002;74:S1318-22.

15. Ehrlich W, Skwara W, Klovekorn W, Roth M, Bauer EP. Do patients want minimally invasive aortic valve replacement? Eur J Cardiothorac Surg. 2000;17:714-7.

16. Farhat F, Lu Z, Lefevre M, Montagna P, Mikaeloff P, Jegaden O. Prospective comparison between total sternotomy and ministernotomy for aortic valve replacement. J Card Surg. 2003;18:396-401.

17. Imazeki T, Irie Y. [Aortic valve replacement through a partial sternotomy. Japanese] Kyobu Geka. 2006;59:650-5.

18. Lee JW, Lee SK, Choo SJ, Song H, Song MG. Routine minimally invasive aortic valve procedures. Cardiovasc Surg. 2000;8:484-90.

19. Leshnower BG, Trace CS, Boova RS. Port-access-assisted aortic valve replacement: a comparison of minimally invasive and conventional techniques. Heart Surg Forum. 2006;9:E560-4.

20. Liu J, Sidiropoulos A, Konertz W. Minimally invasive aortic valve replacement (AVR) compared to standard AVR. Eur J Cardiothorac Surg. 1999;16(Suppl. 2):S80-3.

21. Mächler HE, Bergmann P, Anelli-Monti M, Dacar D, Rehak P, Knez I, et al. Minimally invasive versus conventional aortic valve operations: a prospective study in 120 patients. Ann Thorac Surg. 1999;67:1001-5.

22. Masiello P, Coscioni E, Panza A, Triumbari F, Preziosi G, Di Benedetto G. Surgical results of aortic valve replacement via partial upper sternotomy: comparison with median sternotomy. Cardiovasc Surg. 2002;10:333-8.

23. Mihaljevic T, Cohn LH, Unic D, Aranki SF, Couper GS, Byrne JG. One thousand minimally invasive valve operations: early and late results. Ann Surg. 2004;240: 529-34.

24. Stamou SC, Kapetanakis EI, Lowery R, Jablonski KA, Frankel TL, Corso PJ. Allogeneic blood transfusion requirements after minimally invasive versus conventiona aortic valve replacement: a risk-adjusted analysis. Ann Thorac Surg. 2003;76:1101-6.

25. Suenaga E, Suda H, Katayama Y, et al. Comparison of limited and full sternotomy in aortic valve replacement. Jpn J Thorac Cardiovasc Surg. 2004;52:286-91.

26. Szwerc MF, Benckart DH, Wiechmann RJ, Savage EB, Szydlowski GW, Magovern GJ Jr, et al. Partial versus full sternotomy for aortic valve replacement. Ann Thorac Surg. 1999;68:2209-13.

27. Vanoverbeke H, Van Belleghem Y, Francois K, Caes F, Bove T, Van Nooten G. Operative outcome of minimal access aortic valve replacement versus standard procedure. Acta Chir Belg. 2004;104:440-4.

28. Walther T, Falk V, Metz S, Diegeler A, Battellini R, Autschbach R, et al. Pain and quality of life after minimally invasive versus conventional cardiac surgery. Ann Thorac Surg. 1999;67:1643-7.

29. Bridgewater B, Steyn RS, Ray S, Hooper T. Minimally invasive aortic valve replacement through a transverse sternotomy: a word of caution. Heart. 1998;79:605-7.

30. Society of Thoracic Surgeons Blood Conversation Guideline Task Force, Ferraris VA, Ferraris SP, Saha SP, Hessel EA 2nd, Haan CK, et al. Perioperative blood transfusion and blood conservation in cardiac surgery: the Society of Thoracic Surgeons and The Society of Cardiovascular Anesthesiologists clinical practice guideline. Ann Thorac Surg. 2007;83(5 Suppl):S27-86.

31. Ali IM, El-shanafi S, Kinley EC, Clark V. Subtotal median sternotomy for heart surgery. Eur J Cardiothorac Surg. 2000;17:255-9.

32. Tabata M, Umakanthan R, Khalpey Z, Aranki SF, Couper GS, Cohn LH, et al Conversion to full sternotomy during minimal-access cardiac surgery: reasons and results during a 9.5-year experience. J Thorac Cardiovasc Surg. 2007;134: 165-9.

33. Caffarelli AD, Robbins RC. Will minimally invasive replacement ever really be important? Curr Opin Cardiol. 2005;19:123-7.

34. Chitwood WR Jr. Current status of endoscopic and robotic mitral valve surgery. Ann Thorac Surg. 2005;79:S2248-53. 


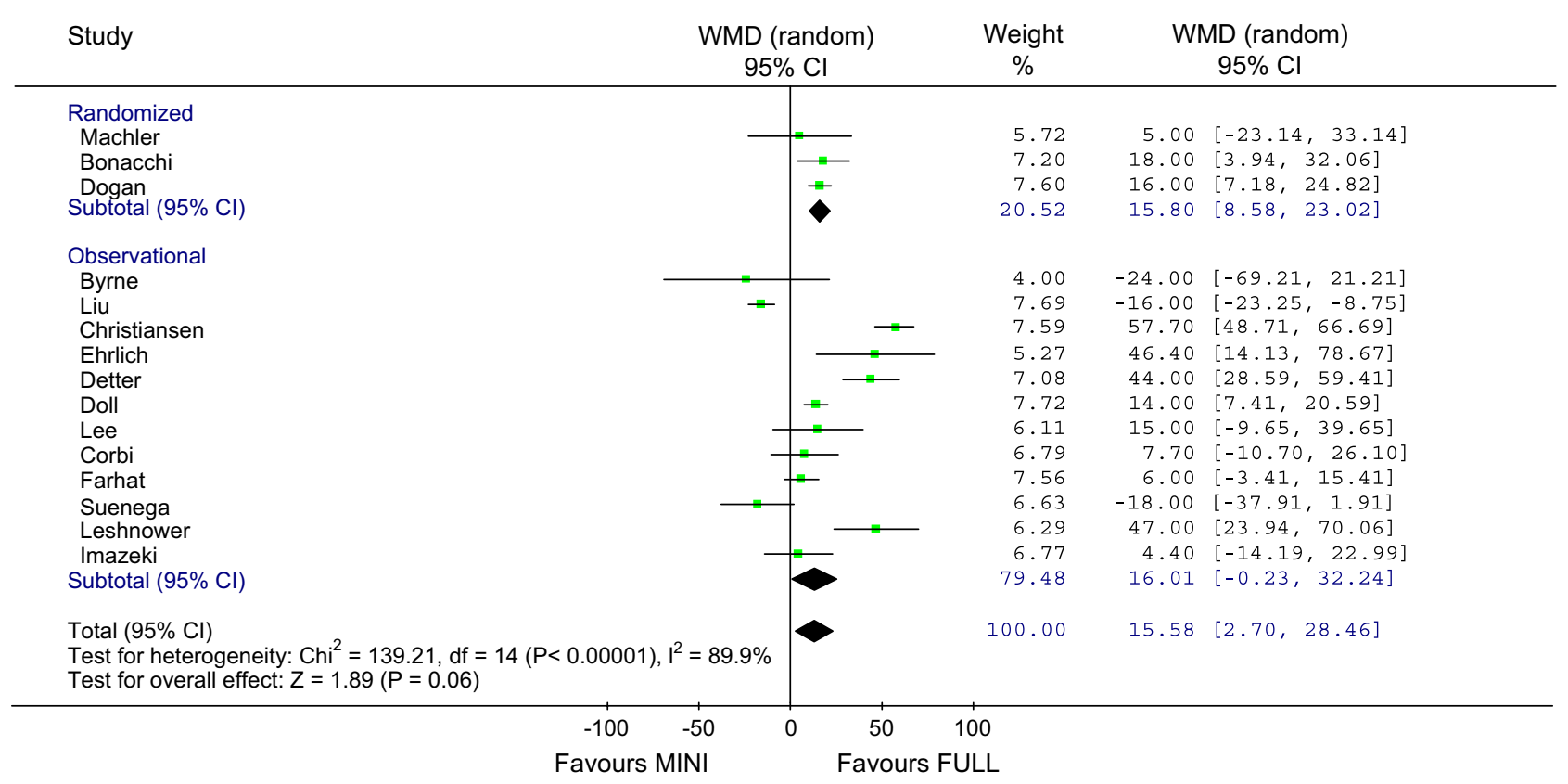

FIGURE E1. Total operative time (in minutes). This figure demonstrates pooled estimates for total operative time. Estimates greater than 1 indicate shorter operative time with full sternotomy approach $(F U L L)$. This is divided into randomized and observational studies. WMD, weighted mean difference; $C I$, confidence interval; $d f$, degrees of freedom; MINI, ministernotomy. 


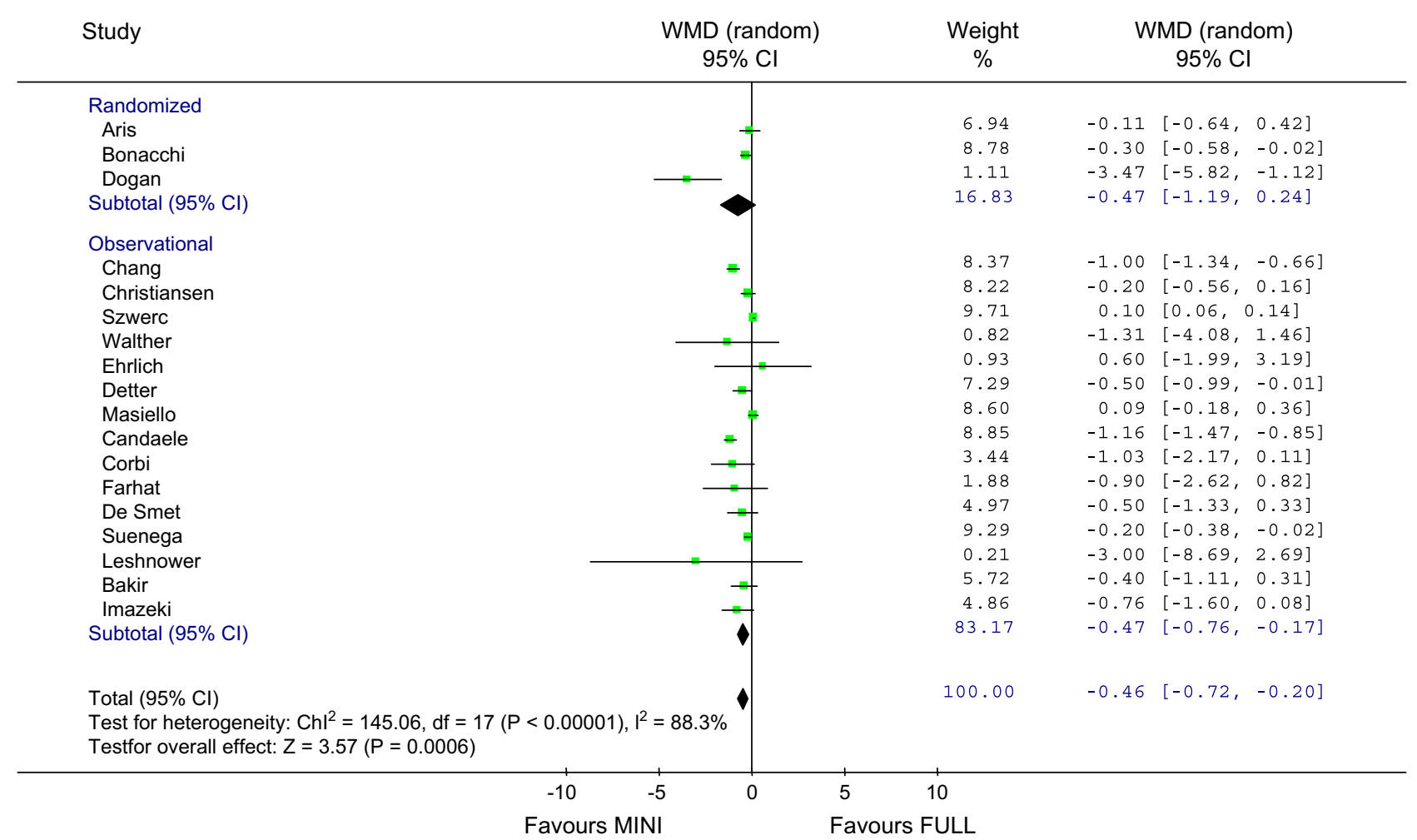

FIGURE E2. Intensive care unit stay (in days). This figure demonstrates pooled estimates for stay in intensive care unit. Estimates less than 1 indicate shorter intensive care stay with ministernotomy approach (MINI). This is divided into randomized and observational studies. WMD, weighted mean difference; $C I$, confidence interval; $d f$, degrees of freedom; FULL, full sternotomy. 


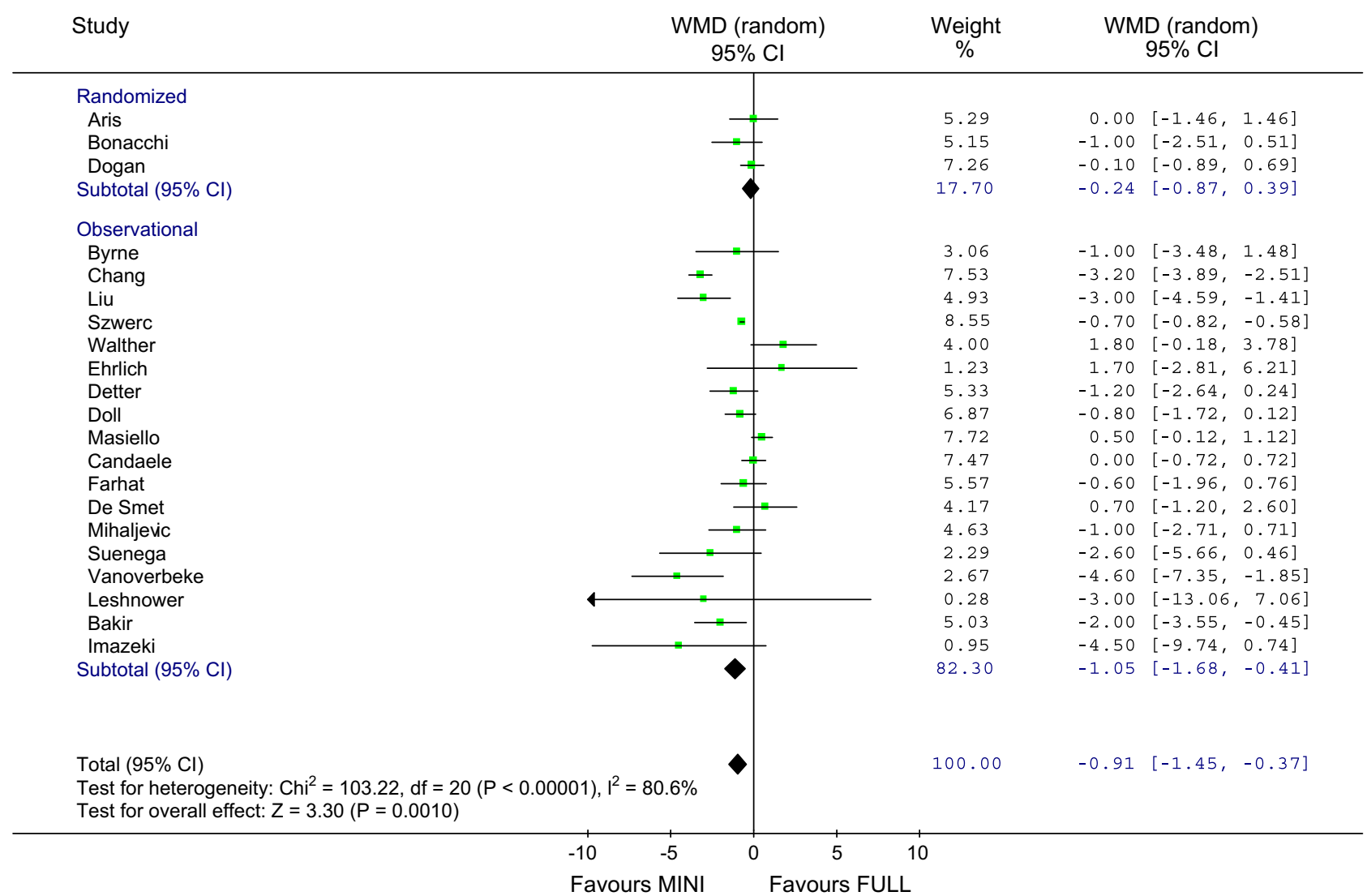

FIGURE E3. Hospital stay(in days). This figure demonstrates pooled estimates for stay in hospital. Estimates less than 1 indicate shorter hospital stay with ministernotomy approach (MINI). This is divided into randomized and observational studies. WMD, weighted mean difference; $C I$, confidence interval; $d f$, degrees of freedom; FULL, full sternotomy. 


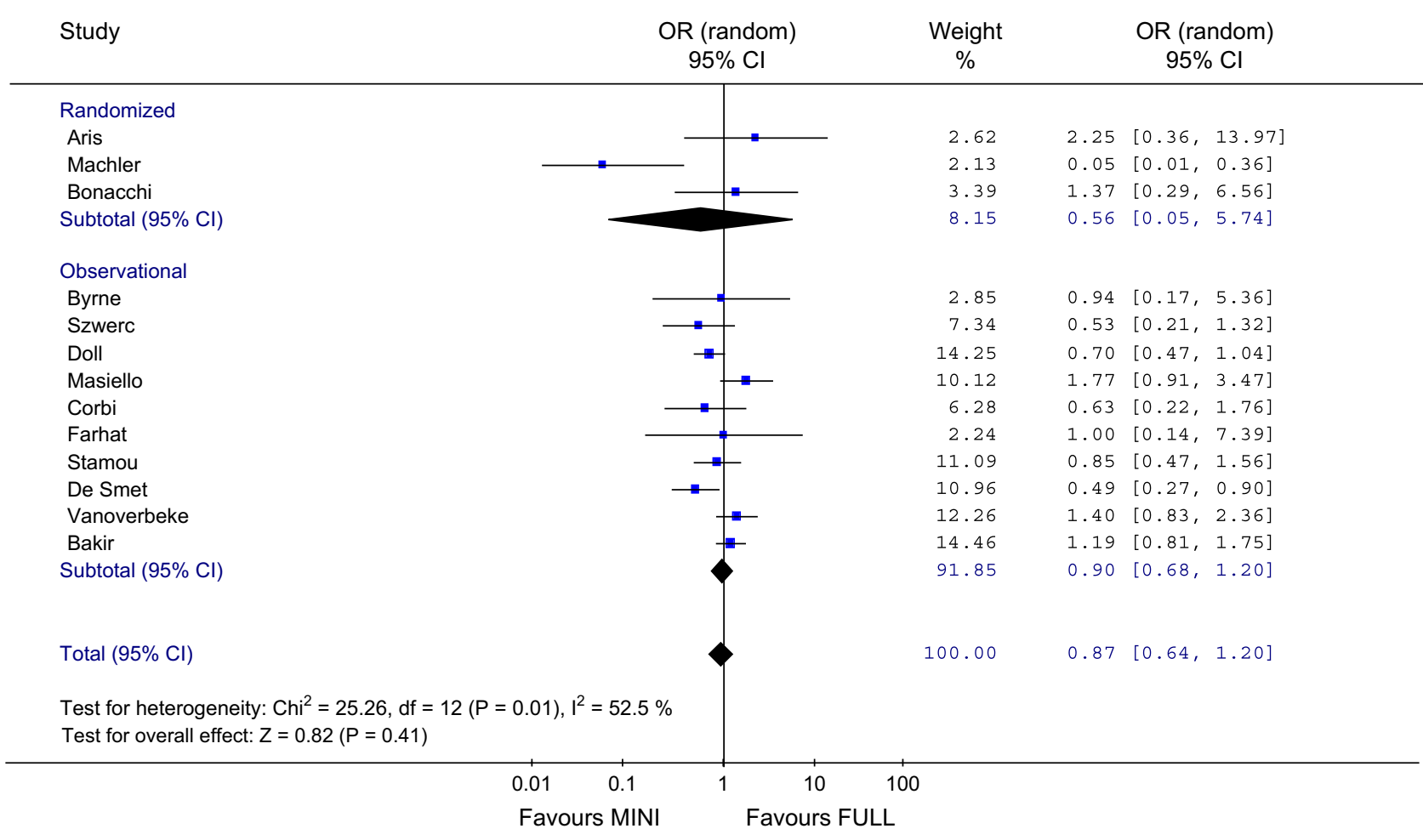

FIGURE E4. Postoperative atrial fibrillation. This figure demonstrates pooled estimates for atrial fibrillation after operation. Estimates less than 1 indicate lower estimates of atrial fibrillation after ministernotomy approach (MINI). This is divided into randomized and observational studies. $O R$, odds ratio; $C I$, confidence interval; $d f$, degrees of freedom; FULL, full sternotomy. 


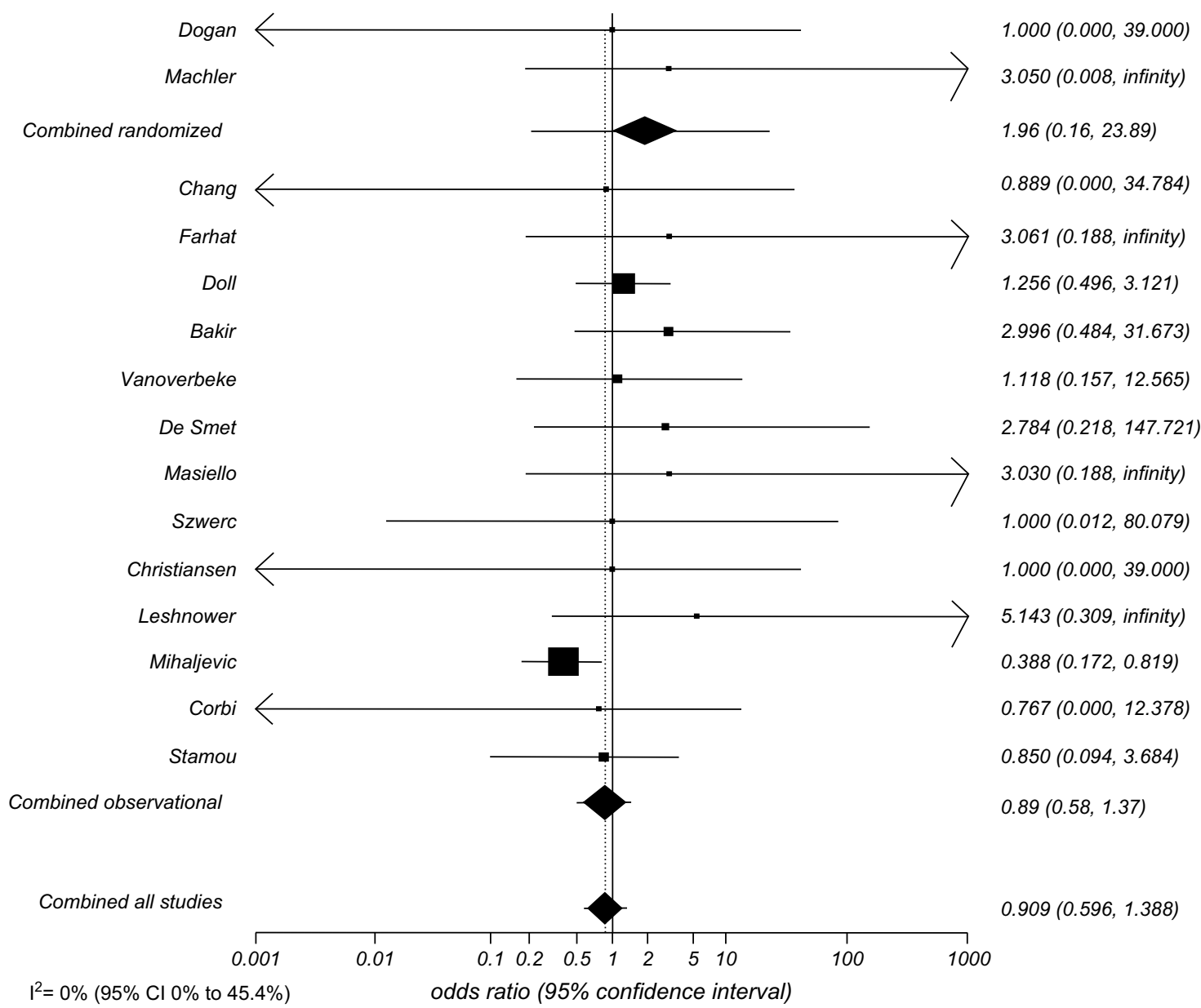

FIGURE E5. Postoperative stroke. This figure demonstrates pooled estimates for postoperative stroke. Estimates less than 1 indicate lower estimate of postoperative stroke with ministernotomy approach. This is divided into randomized and observational studies. CI, Confidence interval. 